Report No. BMI-1249

UC-25 Metallurgy and Ceramics

(TID-4500, 13th Ed., SuppI.)

Contract No. W-7405-eng-g2

THE EFFECT OF PRIMARY ALPHA ON THE BETA DECOMPOSITION

OF ZIRCONIUM-URANIUM-OXYGEN ALLOYS

by

David L. Douglass

Lyle L. Marsh, Jr.

January 14, 1958

BATTELLE MEMORIAL INSTITUTE

505 King Avenue

Columbus 1 , Ohio 


\section{DISCLAIMER}

This report was prepared as an account of work sponsored by an agency of the United States Government. Neither the United States Government nor any agency Thereof, nor any of their employees, makes any warranty, express or implied, or assumes any legal liability or responsibility for the accuracy, completeness, or usefulness of any information, apparatus, product, or process disclosed, or represents that its use would not infringe privately owned rights. Reference herein to any specific commercial product, process, or service by trade name, trademark, manufacturer, or otherwise does not necessarily constitute or imply its endorsement, recommendation, or favoring by the United States Government or any agency thereof. The views and opinions of authors expressed herein do not necessarily state or reflect those of the United States Government or any agency thereof. 


\section{DISCLAIMER}

Portions of this document may be illegible in electronic image products. Images are produced from the best available original document. 


\section{TABLE OF CONTENTS}

Page

ABSTRACT.

INTRODUCTION

EXPERIMENTAL PROCEDURES.

Alloy Preparation. . . . . . . . . . . . . . . . . . 2

Heat Treatment . . . . . . . . . . . . . . . . . . 2

Metallography . • . . . . . . . . . . . . . . . . . 2

$\mathrm{X}$-Ray Diffraction. . . . . . . . . . . . . . . . 2

CONSTITUTION OF ALLOYS . . . . . . . . . . . . . . . . . . . . 3

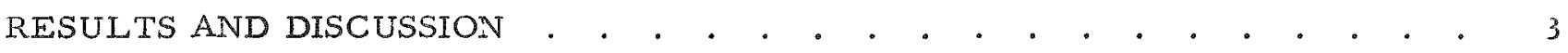

Transformation Kinetics . . . . . . . . . . . . . . . . . 3

Nominal Zirconium-7 w/o Uranium Alloys . . . . . . . . . 0

Nominal Zirconium-10 w/o Uranium Alloys . . . . . . . . 8

Nominal Zirconium-15 w/o Uranium Alloys . . . . . . . . . 9

Correlation of Microstructure With Heat Treatment . . . . . . . . 9

Nominal Zirconium-7 w/o Uranium Alloys . . . . . . . . . y

Nominal Zirconium-10 w/0 Uranium Alloys . . . . . . . . 14

Nominal Zirconium-15 w/o Uranium Alloys . . . . . . . . . 14

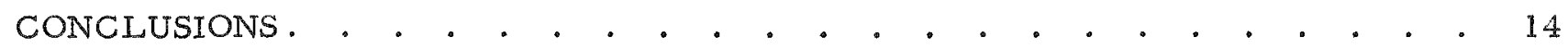

REFERENCES . . . . . . . . . . . . . . . . . . . . 15 


\title{
THE EFFECT OF PRIMARY ALPHA ON THE BETA DECOMPOSITION OF ZIRCONIUM-URANIUM-OXYGEN ALLOYS
}

\author{
David L. Douglass and Lyle L. Marsh, Jx.
}

The effect of primary alpha present during the solution-treating cycle on the incubation period for the decomposition of beta and on the resultant structure has been determined for zirconium-base alloys containing from 7 to 15 $w$ 'o uranium and from 0.094 to $0.29 \mathrm{w} / \mathrm{o}$ oxygen.

Prior-existing alpha decreased the time at which precipitation of Widmanstätten alpha started and increased the rate of precipitation. The microstructure of transformed alloys was correlated with tentative isothermaltransformation diagrams.

\section{IN TRODUCTION}

Commercial heat treatments are designed to produce certain strength and toughness characte-istics by controlling the microstructure of an alloy. A desired distribution of microconstituents is achieved in practice by treating an alloy under the correct time-temperature conditions. A knowledge of the phase equilibria in any alloy system is essential in outlining heat treatments, but in addition, the transformation kinetics of the solid-state reactions must be known. The kinetics are particularly important when the heat treatment is the so-called isothermal-transformation (inter rupted quench) treatment. The effect of time at various temperatures on the size, shape, distribution, and amount of a second phase is significant.

Due to either contamination or simply the oxygen content of sponge, most zirconium-base alloys are at least ternary alloys. Contamination by oxygen results in an inc rease in the alpha/alpha plus beta transus (stabilization of alpha), and consequently solution treatment is generally performed in the two-phase region, alpha plus beta, for even relatively small oxygen contents. Excessively high temperatures of $1300 \mathrm{C}$ or higher would be required to solution treat zirconium-uranium alloys containing up to $0.3 \mathrm{w} / \mathrm{o}$ oxygen entirely within the beta region. It was thus decided to investigate the effect of the pre-existing primary alpha phase, which of necessity would be present during solution treatment, on the subsequent transformation behavior of zirconiumuranium-oxygen alloys.

The zirconium-uranium alloy system is particularly sensitive to isothermal transformation of beta at subcritical temperatures. (1) The effect of oxygen has been observed to be significant on the phase equilibria and transformation kinetics of both titanium and zirconium alloys. In this work, two levels of oxygen were investigated, 0.094 and $0.29 \mathrm{w} / 0$. These contents were chosen to simulate alloys produced from nominal-purity sponge zirconium and slightly contaminated alloys, respectively. These contents are more representative of actual alloys than the high-purity crystal-bar alloys used in previous work. (1)

(1) References at sutu. 
EXPERIMENTAL PROCEDURES

\section{Alloy Preparation}

All alloys were prepared by double arc melting of consumable electrodes in vacuum. The clectrodes were prepared by compacting sponge-zirconium and biscuit uranium for the lower oxygen level; small additions of zirconia were compacted with the metal for the alloys with the higher oxygen content. The ingots were forged at $800 \mathrm{C}$ and subsequently rolled to $0.075-i n$. sheet at $700 \mathrm{C}$. Chemical analyses of the alloys are listed in Table 1.

TABLE 1. CHEMICAL ANALYSES OF EXPERIMENTAL ALLOYS

\begin{tabular}{|c|c|c|c|c|}
\hline \multicolumn{5}{|c|}{ Composition, w/o } \\
\hline \multicolumn{2}{|c|}{ Uranium } & \multicolumn{2}{|c|}{ Oxygen } & \multirow{2}{*}{$\begin{array}{c}\text { Analyzed } \\
\text { Carbon }\end{array}$} \\
\hline Nonimal & Analyzed & Nominal & Analyzed & \\
\hline 7 & 6.6 & 0.094 & 0.094 & 0.08 \\
\hline 10 & 9.5 & 0.094 & 0.094 & 0.14 \\
\hline 15 & 15.6 & 0.094 & 0.094 & 0.10 \\
\hline 7 & 6.9 & 0.29 & 0.27 & (a) \\
\hline 10 & 9.6 & 0.29 & 0.24 & (a) \\
\hline 15 & 14.3 & 0.29 & 0.27 & (a) \\
\hline
\end{tabular}

(a) Not andlyzed but should be similar to $0.094 \mathrm{~W} / \mathrm{o}$ oxygen alloys.

\section{Heat Treatment}

Samples, $1 / 4 \mathrm{in}$. square, of the sheet stock were used for the isothermal-transformation studies. The specimens were individually sealed in 3/8-in.-diametex Type 304 stainless steel tubing welded shut at both ends. The capsules were attached to Nichrome wire and suspended in a solution-treating salt bath at $1000 \mathrm{C}$ for $1 \mathrm{hr}$. The capsules were then quenched into the isothermal-transformation bath at the desired temperature, held for a given time, and water quenched to room temperature.

\section{Metallography}

Transformation samples were mounted in Bakelite, ground through a b00-grit silicon carbide wheel, polished with Blue Diamond abrasive on Forstmann cloth, and etched in a solution of $30 \mathrm{ml}$ of $\mathrm{HNO}_{3}, 30 \mathrm{ml}$ of lactic acid, and 6 drops of $\mathrm{HF}$.

\section{X-Ray Diffraction}

Diffraction patterns were made with a 57.3-mm Debye camera on a rotating sliver, $0.025 \mathrm{in}$. in diameter, tapered to a fine point. The slivers were etched from bars 1/16 in. square with a solution consisting of $15 \mathrm{ml}$ of lactic acid, $20 \mathrm{ml}$ of $\mathrm{HNO}_{3}$, and $10 \mathrm{ml}$ of $\mathrm{HF}$. Filtered radiation was used with an iron target. 


\section{CONSTITUTION OF ALLOYS}

The phase diagram for binary zirconium-uranium alloys is shown in Figure 1. (2) The addition of uranium to zirconium decreases the alpha-beta transformation temperature to a eutectoid at $44 \mathrm{w} / 0$ uranium and $595 \mathrm{C}$. At room temperature the stable phases in the binary system containing up to about $43 \mathrm{w} / 0$ uranium are alpha zirconium and epsilon (an intermediate phase having a hexagonal-close-packed structure that extends over a range of compositions).

The influence of oxygen on the alpha-beta transformation in zirconium is marked. (3) Oxygen increases the transformation temperature from $865 \mathrm{C}$ in pure zirconium to $1940 \mathrm{C}$ at $2 \mathrm{w} / 0$ oxygen. When both oxygen and uranium are added to zirconium, opposite effects are encountered for each element. The only phase diagram available for this system, an isothermal section of the ternary system at $1095 \mathrm{C}^{(4)}$, is shown in Figure 2 .

\section{RESULTS AND DISCUSSION}

The first portion of this investigation was aimed at determining the uranium content of the beta phase present during solution treatment. Samples were quenched from $1000 \mathrm{C}$, and the volume fraction of primary alpha was measured by point counting. The uranium content of the beta phase was then calculated. In all but one case, the uranium content of the beta, which subsequently transformed, was greater than the uranium content of the alloy itself. These data are shown in Table 2.

\section{Transformation Kinetics}

The distribution coefficient of oxygen between alpha and beta is thought to be 45 or greater. (5) Therefore, the oxygen content of the beta phase obtained during solution treatment is low and could be considered to a first approximation as negligible. It should be noted that, as the oxygen content of a series is increased, the oxygen content of the beta will increase. However, due to the large distribution coefficient between alpha and beta phases, the stabilization of alpha has been considered to be the important parameter in affecting transformation behavior of two-phase alloys rather than the oxygen content of the beta. It might seem that the transformation behavior of the alloys would be similar to binary alloys, since the alpha present at $1000 \mathrm{C}$ is changed very little during subsequent transformation. Unfortunately, this simplified picture is not indicative of the actual phenomena. The presence of the alpha phase during solution treatment apparently changes the energy requirements for nucleation of transformation products. Any resultant effect of composition is difficult to evaluate because an overall change in alloy composition results in an interdependent compositional change of each phase. Hence, only a semiquantitative picture of the transformation behavior of each nominal composition will be presented.

\footnotetext{
The quenched structure consisted of alpha in equilibrium with beta at $1000 \mathrm{C}$ and martensitic alpha fonned by beta decomposition.
} 


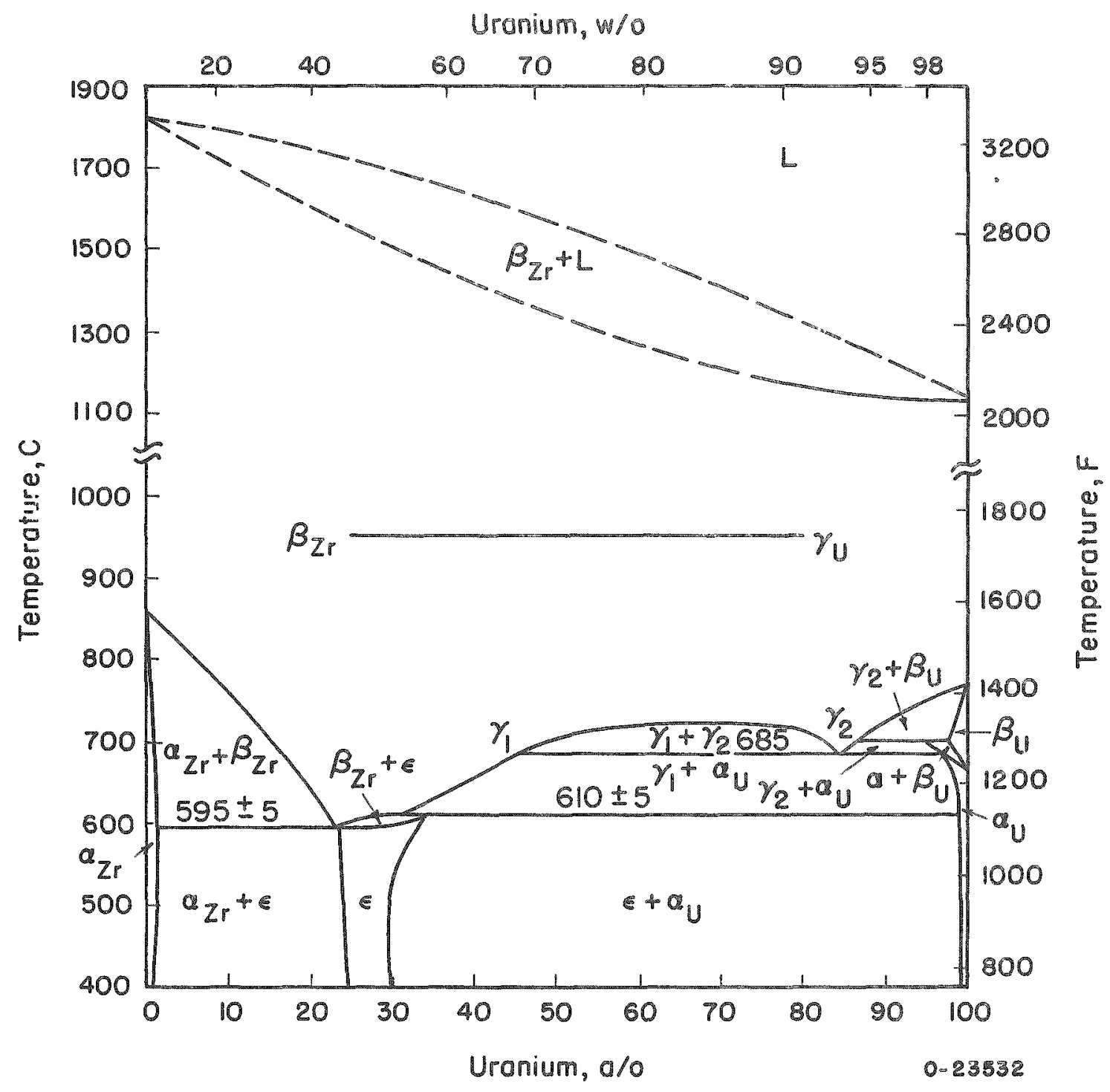

FIGURE 1. ZIRCONIUN-URANIUM CONSTITUTIG IV DIAGRAM From Reference (2). 


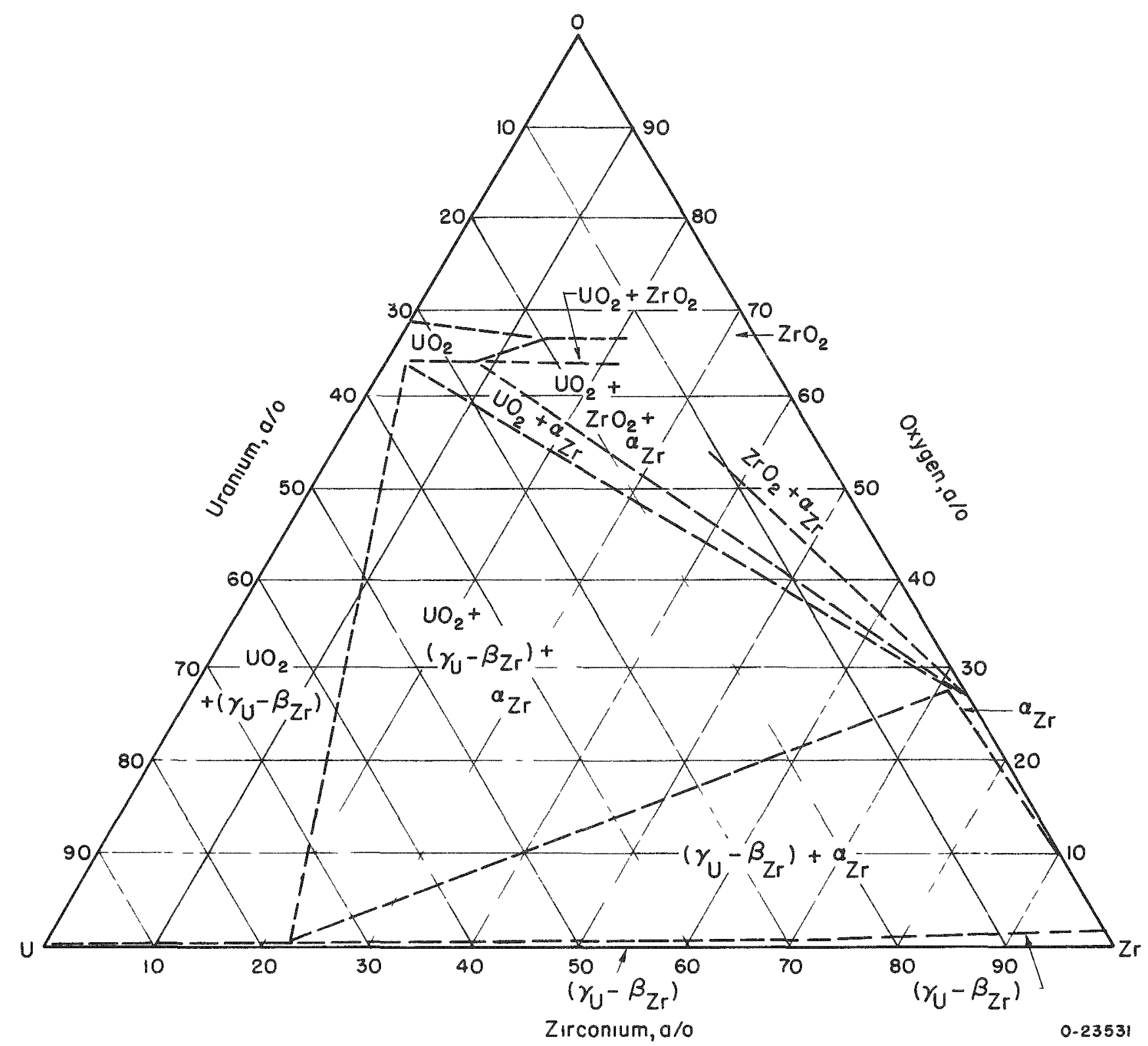

FIGURE 2. TENTATIVE ZIRCONIUM-URANIUM-OXYGEN TERNARY SECTION AT $1095 \mathrm{C}$

From Reference (4). 
TABLE 2. URANIUM CONTENT OF BETA PHASE OBTAINED

DURING SOLUTION TREATING AT $1000 \mathrm{C}$

\begin{tabular}{cccc}
\hline \hline $\begin{array}{c}\text { Nominal Compozition } \\
\text { (Balance Zirconium), } \\
\text { w/o }\end{array}$ & Uranium Content & $\begin{array}{c}\text { Average } \\
\text { of Beta, w/o }\end{array}$ & $\begin{array}{c}\text { Alpha Content (a) } \\
\text { volume per cent }\end{array}$ \\
\hline Uranium & Oxygen & 7 & 0 \\
\hline 7 & 0.094 & 11.8 & 4 \\
10 & 0.094 & 17.1 & $12.3(\mathrm{~b})$ \\
15 & 0.094 & 8.2 & 12.0 \\
7 & 0.29 & 12.6 & 9.1 \\
10 & 0.29 & 16.8 & 7.8 \\
15 & 0.29 & & \\
\hline
\end{tabular}

(a) Solution treated 50 hr at $1000 \mathrm{C}$, water quenched.

(b) Questionable value, probably contaminated by oxygen during solution treating.

Nominal Zirconium-7 w/o Uranium Alloys

Alpha precipitation in binary zirconium-uranium alloys initiated readily at $700 \mathrm{C}$, requiring less than 1 min to start. The addition of $0.094 \mathrm{w} / 0$ oxygen shifted the " $\mathrm{C}$ " curve for the alpha precipitation to the left so that the reaction took place within shorter times at temperature. No alpha existed in this alloy at $1000 \mathrm{C}$, the refore, it can be stated unequivocally that oxygen accelerated the precipitation of alpha.

A further increase in the oxygen content to $0.29 \mathrm{w} / 0$ resulted in the stabilization of 12.0 volume per cent alpha at $1000 \mathrm{C}$. The beta in equilibrium with this alpha was en riched in uranium and should, therefore, be expected to transform slower than the nominal $7 \mathrm{w} / 0$ binary alloy. However, the effect of the primary alpha was opposite to that of the beta enrichment by uranium, and the time at which alpha precipitation initiated was intermediate to that of the binary alloy and the $0.094 \mathrm{w} / 0$ oxygen ternary alloy.

An $\mathrm{M}_{\mathrm{S}}$ temperature could not be clearly defined in the $0.29 \mathrm{w} / 0$ oxygen alloy, primarily because of the small difference in the metallographic appearance of Widmanstatten alpha formed at low temperatures and martensitic alpha.

It was thought that the lack of metallographic difference in alpha prime (martensite) and Widmanstätten alpha might be circumvented by lattice-parameter measurements, and thus the $\mathrm{M}_{\mathrm{S}}$ temperature could be determined. The lattice parameters of martensitic alpha should decrease with increasing uranium content, since the lattice parameter of the body-centered-cubic high-temperature phase decreases with increasing uranium. However, reflections from the oxygen-rich primary alpha masked the alpha-prime reflections, largely because the high oxygen content of the primary alpha expanded the lattice. In addition, considerable line broadening was encountered due to transformation strains. A comparison of lattice parameters is given in Table 3 for high-oxygen low-uranium equilibrium alpha and for a lower oxygen high-uranium quenched alpha. Little difference existed; certainly not enough to distinguish alpha from alpha prime. 
TABLE 3. LATTICE PARAMETERS OF ALPHA IN EQUILIBRIUM AND IN QUENCHED ALLOYS

\begin{tabular}{|c|c|c|c|c|}
\hline \multicolumn{2}{|c|}{$\begin{array}{c}\text { Nominal Composition } \\
\text { (Balance Zirconium), } \\
\text { w/o }\end{array}$} & \multirow[b]{2}{*}{ Heat Treatment } & \multicolumn{2}{|c|}{$\begin{array}{c}\text { Lattice Parameter, } \\
\mathrm{A} \\
\end{array}$} \\
\hline Uranium & $\overline{\text { Oxygen }}$ & & $a_{0}$ & $c_{0}$ \\
\hline 7 & $=-$ & Slow cooled & 3.231 & 5.147 \\
\hline 15 & -- & Ditto & 3. 231 & 5.147 \\
\hline 7 & 0.428 & Ditto & 3.236 & 5.162 \\
\hline 15 & 0.29 & $\begin{array}{l}\text { Quenched from } \\
1000 \mathrm{C} \text { to } 550 \mathrm{C}, \\
\text { held } 1 \mathrm{~min}, \\
\text { water quenched }\end{array}$ & 3.237 & 5.158 \\
\hline
\end{tabular}

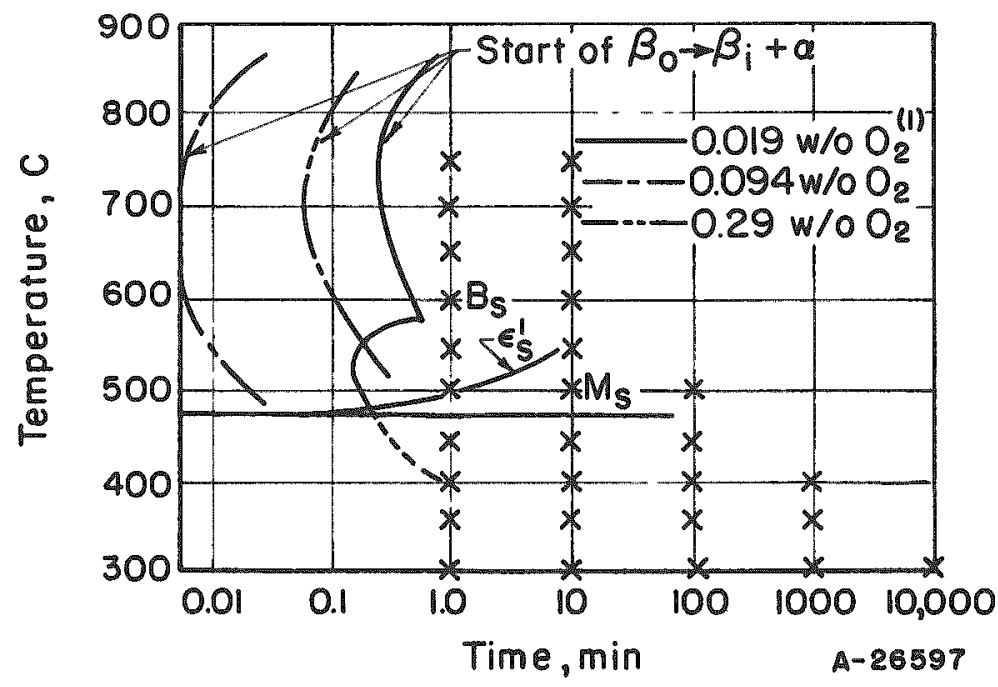

FIGURE 3. SCHEMATIC T-T-T DIAGRAM FOR NOMINAL ZIRCONIUM-7 w/O URANIUM ALLOYS 
Small amounts of the intermediate phase, epsilon, were detected by X-ray diffraction in the temperature range of 300 to $400 \mathrm{C}$ within $100 \mathrm{~min}$ at temperature. The amounts detected were less than in binary zirconium-uranium allcys transformed for the same time in this temperature range. Thus, it can be concluded that primary alpha retarded formation of epsilon. Further, no epsilon prime, a phase transitional to epsilon and supersaturated with zirconium, was observed.

A summary of the start of beta decomposition is given in Figure 3 for nominal 7 w/o uranium alloys containing oxygen. Included for comparison are the results of an earlier study(1) describing the decomposition behavior of binary zirconium-uranium alloys of low oxygen content.

\section{Nominal Zirconium-10 w/o Uranium Alloys}

As shown in Table 2 the addition of $0.094 \mathrm{w} / 0$ oxygen to zirconium-10 w/o uranium alloys stabilized 4.0 volume per cent alpha at $1000 \mathrm{C}$. An increase in the oxygen content to $0.29 \mathrm{w} / 0$ stabilized 9.1 volume per cent alpha at this temperature. The presence of 4.0 volume per cent alpha decreased the stability of beta at subcritical temperatures. However, an increase in the volume per cent alpha to 9.1 resulted in longer periods of beta stability, intermediate to the zero and 4.0 volume per cent alpha alloys. It is not possible to evaluate the individual effects of oxygen and uranium on beta stability because the uranium content of the beta and the volume fraction of the beta are highly sensitive to small variations in the oxygen content of the alloy. Schematic curves for the decomposition of beta for the three alloys of nominal $10 \mathrm{w} / 0$ uranium are shown in Figure 4.

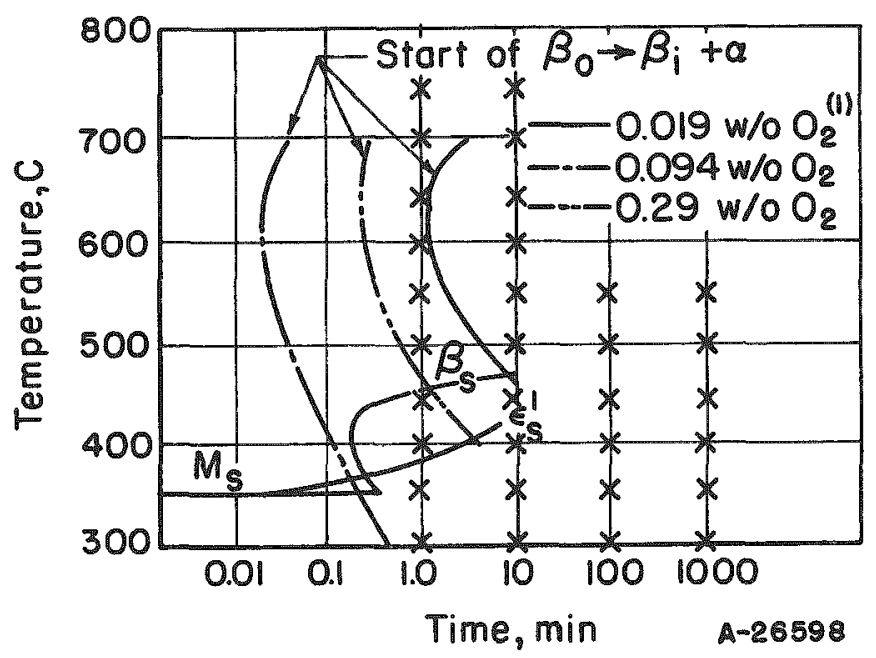

FIGURE 4. SCHEMATIC T-T-T DIAGRAMS FOR ZIRCONIUM-10 w/O URANIUM ALLOYS

No epsilon prime was observed by either $\mathrm{X}$-ray diffraction or by metallographic inspection in either the 0.094 or the $0.29 \mathrm{w} / 0$ oxygen alloys. The phase had been detected in binary alloys transformed at $350 \mathrm{C}$. The absence of epsilon prime at $300 \mathrm{C}$ or above in the ternary alloys does not preclude the possibility that the supersaturated phase forms at temperatures below $300 \mathrm{C}$. 
$M_{S}$ temperatures for these alloys were not determined. The rapid precipitation of Widmanstatten alpha resulted in transformation of nearly all the beta by the time the temperature had decreased to the range in which martensitic alpha usually forms. The effect of the primary alpha on the martensite transformation is unknown.

Nominal Zirconium-15 w/o Uranium Alloys

Transformation of the $15 \mathrm{w} / \mathrm{O}$ uranium alloys was characterized by the appearance of epsilon prime at lower temperatures. Transformation at higher temperatures resulted in large amounts of Widmanstätten alpha within short times. The times at which the various reactions start are summarized in the $T-T-T$ curves in Figure 5.
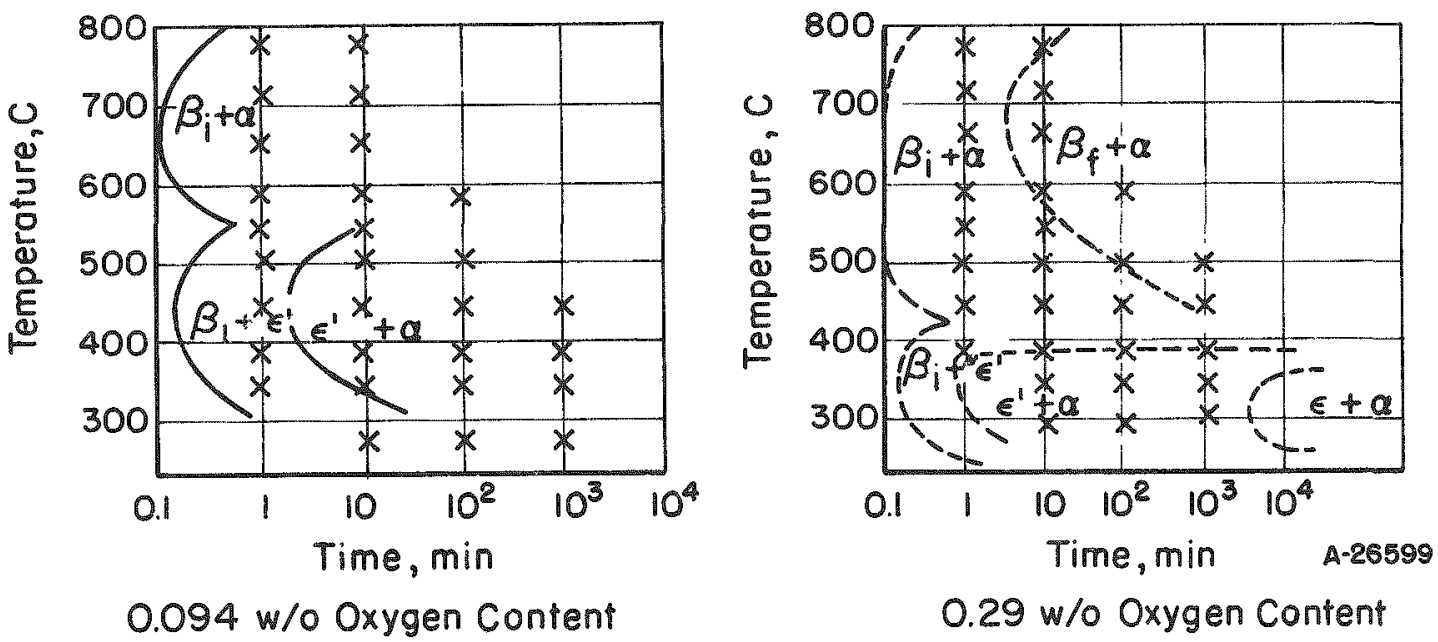

\section{FIGURE 5. SCHEMATIC T-T-T DIAGRAMIS FOR ZIRCONIUM- $15 \mathrm{w} / 0$ URANIUM ALLOYS}

The formation of metastable epsilon prime is shown as an isothermal process, although there is still some uncertainty as to whether the phase formed isothermally or athermally. The epsilon-prime phase decomposed isothermally by a tempering reaction, precipitating alpha until equilibrium epsilon remained. The effect of primary alpha on the tempering of epsilon prime is to lower the temperature at which alpha may be rejected and to increase the time at which the rejection starts. There is however, one temperature, $400 \mathrm{C}$, in the $0.29 \mathrm{w} / 0$ oxygen alloy at which the metastable phase has unusual stability. No precipitation of alpha was observed within $10,000 \mathrm{~min}$; the curve for the rejection of alpha from epsilon prime in this alloy may be nearly horizontal just below $400 \mathrm{C}$.

\section{Correlation of Microstructure With Heat Treatment}

Nominal Zirconium-7 w/o Uranium Alloys

The effect of primary alpha on the microstructure of transformed alloys was pronounced. Solution treatment of the $0.094 \mathrm{w} / 0$ oxygen alloy at $1000 \mathrm{C}$ was performed 
entirely within the beta. region, whereas at this temperature the $0.29 \mathrm{w} / 0$ oxygen alloy was in the alpha-plus-beta region. The net result was that large equiaxed particles of alpha were observed in all microstructures of the alloys with the higher oxygen content regaxdless of the heat treatment. In addition to the equiaxed alpha, the structures consisted of Widmanstätten alpha as part of the matrix.

The nature of the Widmanstätten precipitate for the $0.29 \mathrm{w} / 0$ oxygen alloys depended upon the isothermal transformation temperature. For example, at relatively high temperatures of 650 to $750 \mathrm{C}$, the alpha precipitate was coarse, but, at lower temperatures, less than $550 \mathrm{C}$, the alpha plates were somewhat finer and longer. A comparison between the high- and low-temperature precipitates may be seen in Figure 6 for an alloy transformed 1 min at $750 \mathrm{C}$ compared with 100 min at $500 \mathrm{C}$.

An interesting aspect of these structures is the duplex etching characteristic, indicating a composition gradient across the equiaxed-alpha particles. This behavior may be the result of two phenomena. First, the amount of alpha present at room temperature, prior to solution treatment, was greater than at $1000 \mathrm{C}$. During solution treatment, the epsilon transformed to the stable high-temperature beta phase, but since there is less alpha stable at this temperature than at room temperature, some alpha must go into solution. However, the nucleating sites for the dissolved alpha probably remain around the periphery of the undissolved alpha. (6) Nearly all the oxygen was in the alpha phase, the beta being essentially oxygen free. Cooling of the beta to the isothermal-transformation temperature resulted in precipitation of alpha both as a Widmanstätten precipitate and as an envelope around the existing alpha particles at the prior nucleating sites. The envelope of alpha had a much lower oxygen content because it formed from beta which was nearly oxygen free. Consequently, a region of alpha which was low in oxygen was surrounding a high-oxygen particle of alpha, and the etching characteristics varied. As the time of transformation was increased, the diffusion of oxygen tended to smooth out the gradient, and the duplex etching behavior gradually disappeared.

A second possible mechanism is as follows: If alpha precipitated other than as an envelope around pre-existing alpha from the oxygen-free beta, a state of nonequilibrium existed, with respect to the oxygen content of the two types of alpha. A thermodynamic adjustment occurred until the oxygen composition was the same for both types of alpha. Oxygen diffused from the periphery of the pre-existing alpha to the low-oxygen alpha until equilibrium was established. The diffusion of oxygen from the periphery of the equiaxed alpha left a composition gradient which was observed by etching. As the time at temperature was increased, this gradient disappeared by diffusion of oxygen within the alpha particle. The existence of such behavior was verified by the absence of a growth interface (grain boundary in the primary alpha) on the specimen after removal of the etched surface. Similarly, a growth interface was observed on some particles during examination of the polished surface. It is, therefore, concluded that both mechanisms were operative, i.e., that some precipitation occurred around the prior alpha on the remaining nucleation sites, and the remaining alpha formed as a Widmanstätten precipitate within the grains.

Little structural variation was obtained by heat treatment of the $0.094 \mathrm{w} / \mathrm{O}$ oxygen alloys. All photomicrographs revealed a Widmanstätten alpha of one form or another. As was observed in the higher oxygen alloys, the coarseness of the precipitate was pronounced at higher temperatures. Figure 7 shows a typical sample, a coarse precipitate obtained by holding $100 \mathrm{~min}$ at $700 \mathrm{C}$. 
FIGURE 6. EFFECT OF TEMPERATURE ON THE NATURE OF THE WIDMANSTÄTTEN ALPHA PRECIPITATE IN A ZIRCONIUM-7 w/O URANIUM $=0.29$ w/O OXYGEN ALLOY Note the duplex etching characteristic of the equaxed-alpha particles.

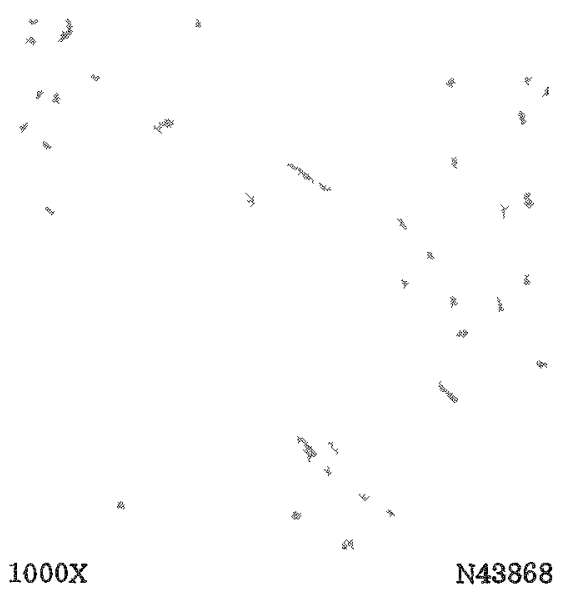

Alloy Transformed $100 \mathrm{Min}$ at $700 \mathrm{C}$

FIGURE 7. TYPICAL HIGH-TEMPERA TURE WIDMANSTÄTTEN ALPHA PRECIPITATE IN A ZIRCONIUM -7 W/O URANIUM $=0.094$ w/O OXYGEN ALLOY 


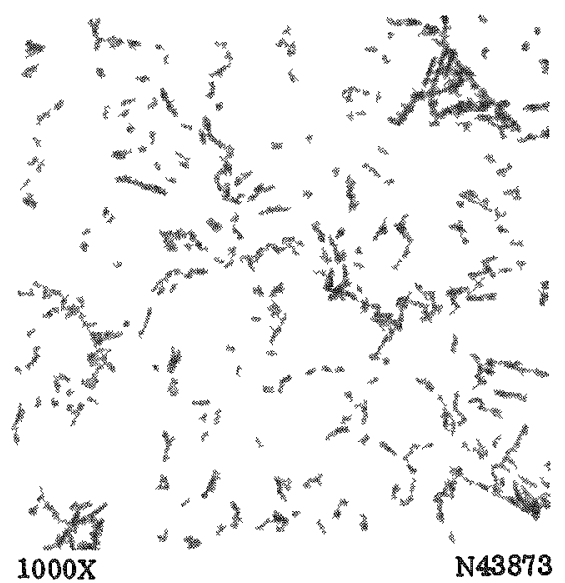

Alloy Transformed $100 \mathrm{Min}$ at $750 \mathrm{C}$

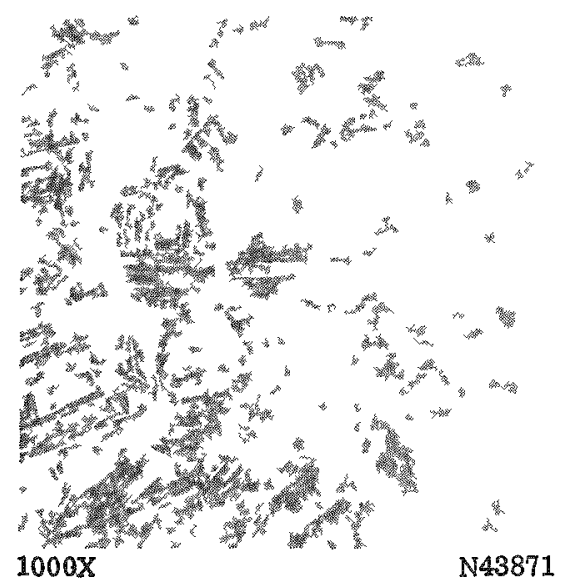

Alloy Transformed $100 \mathrm{Min}$ at $650 \mathrm{C}$

Zirconium-15 w/o Uranium 0.094 w/o Oxygen Alloy

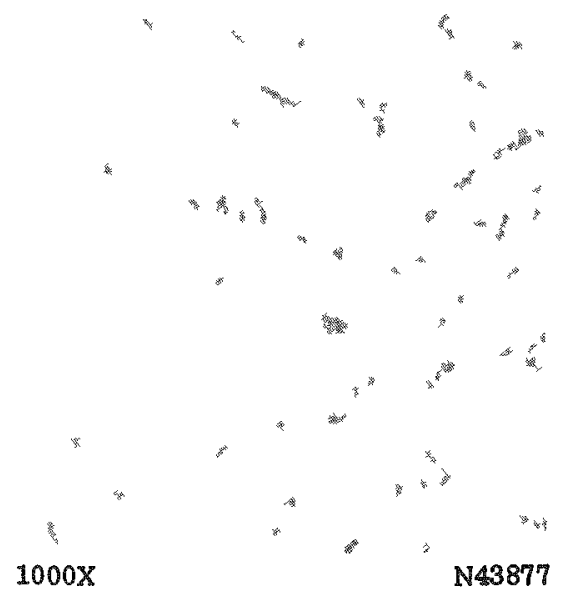

Alloy Transformed 1 Mun at $750 \mathrm{C}$

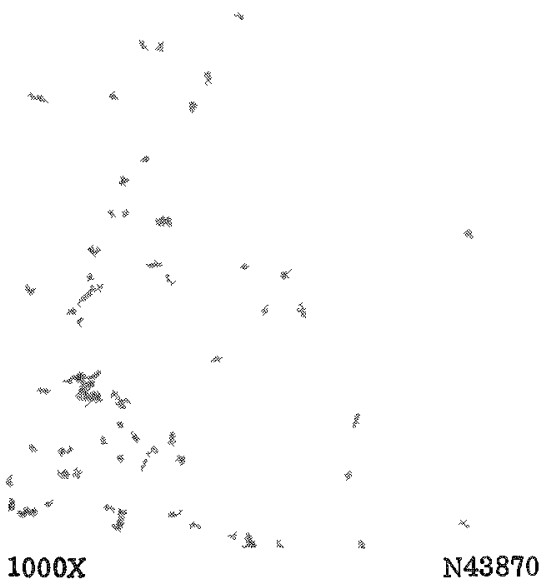

Alloy Transformed $1 \mathrm{Min}$ at $650 \mathrm{C}$

Zirconum=15 w/o Uranium=0.29 w/o Oxygen Alloy

FIGURE 8. THE EFFECT OF TEMPERATURE ON THE SIZE AND SHAPE OF WIDMANSTÄTTEN ALPHA IN ZIRCONIUM-15 W/O URANIUM ALLOYS 


\section{$1000 \mathrm{X}$}

FIGURE 9. TYPICAL EPSILON-PRIME STRUCTURE IN A ZIRCONIUM-15 w/0 URANIUM $-0.29 \mathrm{w} / 0$ OXYGEN ALLOY TRANSFORMED 100 MIN AT $400 \mathrm{C}$

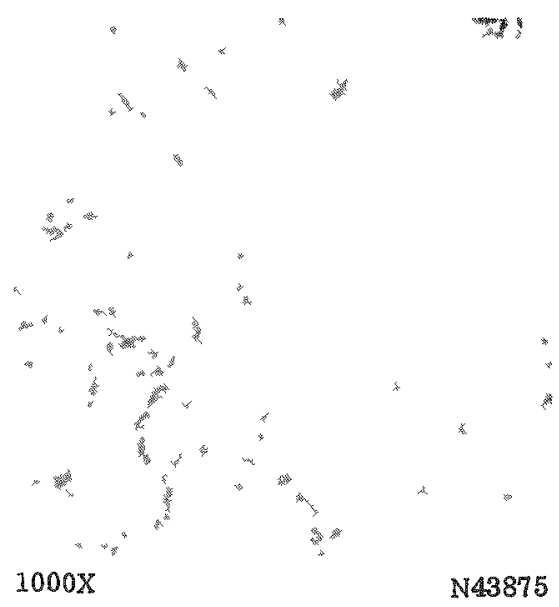

FIGURE 10. ALPHA REJECTION FROM EPSILON PRIME IN A ZIRCONIUM-15 w/o URANIUM $-0.29 \mathrm{w} / 0$ OXYGEN ALLOY TRANSFORMED $10 \mathrm{MIN}$ AT $350 \mathrm{C}$ 
Nominal Zirconium-10 w/o Uranium Alloys

The microstructures of alloys containing $10 \mathrm{w} / \mathrm{o}$ uranium (both oxygen contents) were similar to those of the alloy containing $7 \mathrm{w} / 0$ uranium and $0.29 \mathrm{w} / 0$ oxygen. Basically, the only difference was the time required to produce a given size and quantity of Widmanstätten alpha. Because the kinetics of transformation were slightly more sluggish for the higher uranium alloys, slightly longer times were necessary to produce a given structure.

The zirconium-10 w/o uranium $-0.094 \mathrm{w} / 0$ oxygen alloy contained less equiaxed alpha than the $0.29 \mathrm{w} / 0$ oxygen alloy, but otherwise the microstructures were similar. Due to the more rapid kinetics of precipitation in the lower oxygen alloys, more Widmanstätten alpha was observed in a given transformation time.

Nominal Zirconium-15 w/o Uranium Alloys

In the temperature range of 600 to $750 \mathrm{C}$ the structure of $15 \mathrm{w} / 0$ uranium alloys was similar to that of the $10 \mathrm{w} / 0$ uranium alloys. However, at lower temperatures, both alloys contained considerable epsilon prime.

The $0.094 \mathrm{w} / 0$ oxygen alloys contained less Widmanstätten alpha than the $10 \mathrm{w} / 0$ uranium alloy with the same axygen content in the temperature range of 450 to $600 \mathrm{C}$. The increase in uranium content from 10 to $15 \mathrm{w} / 0$ retarded alpha formation in this temperature range and resulted in structures consisting of equiaxed alpha (present during solution treatment), some Widmanstätten alpha, and epsilon. Figure 8 shows the effect of temperature above the critical temperature on the Widmanstatten alpha precipitate in alloys containing oxygen. Increasing the oxygen content can be observed to greatly increase the amount of Widmanstätten alpha, particularly in the series transformed at $750 \mathrm{C}$.

A typical epsilon-prime structure is shown in Figure 9. Gray equiaxed-alpha particles appeared in a matrix of small subgrains of epsilon prime. A small amount of Widmanstätien alpha formed during the quench through the nose of the curve at $700 \mathrm{C}$.

Rejection of alpha from epsilon prime may be observed in Figure 10. The fine Widmanstätten precipitate extended across the epsilon-prime subgrains, indicating little or no orientation difference between adjacent epsilon-prime grains.

\section{CONCLUSIONS}

The addition of $0.094 \mathrm{w} / 0$ oxygen to a zirconium $-7 \mathrm{w} / 0$ uranium alloy decreased the is othermal holding time for the start of transformation at subcritical temperatures. Oxygen contents of $0.094 \mathrm{w} / 0$ in the 10 and $15 \mathrm{w} / 0$ uranium alloys produced a duplex microstructure of alpha and beta phases at $1000 \mathrm{C}$. The presence of this primary alpha decreased the incubation period for the start of alpha precipitation and increased the rate of precipitation. 
The formation of epsilon was retarded by primary alpha, but in alloys containing $15 \mathrm{w} / \mathrm{o}$ uranium, epsilon prime formed rapidly. The epsilon prime decomposed isothermally to epsilon by precipitating alpha.

No martensitic alpha was observed in alloys quenched from the alpha-plus-beta region. The phase was detected in alloys quenched from the beta region.

The size and shape of Widmanstätten alpha were dependent upon the isothermal transformation temperature. The epsilon-prime structure appeared as small equiaxed subgrains within prior beta grains.

\section{REFERENCES}

(1) Douglass, D. L., Marsh, L. L., Jr., and Manning, G. K., "Transformation Kinetics of Zirconium-Uranium Alloys", ASM Preprint No. 20 (1957).

(2) Rough, F. A., Austin, A. E., Bauer, A. A., and Doig, J. R., "The Stability and Existence Range of the Zirconium-Uranium Epsilon Phase", BMII-1092 (May 28, 1956).

(3) Domagala, R. F., and McPherson, D., "System Zirconium-Oxygen", Journal of Metals, 6 (2), 238 (February 1954).

(4) Saller, H. A., Rough, F. A., Facklemann, J. M., Bauer, A. A., and Doig, J. R., "Phase Relations in the Uranium-Zirconium-Oxygen System Involving Zirconium and Uranium Dioxide", BMI-1023 (July 28, 1955).

(5) Bauer, A. A., Private Communication.

(6) Keeler, J. H., Hibbard, W. R., Jr., and Decker, B. F., "Textures of Rolled and Annealed Iodide Zirconium", Trans. AIME, 197, 932 (1953). 